17 Word Count: 5,123 words (main text)

18 Tables: 2

19 Figures: 4

20 than financial support. screening and running participants.

Brief training in regulation of craving reduces cigarette smoking

\author{
Richard B. Lopez, Ph.D. \\ Department of Psychology, Bard College, Annandale on Hudson, NY, USA \\ Kevin N. Ochsner, Ph.D. \\ Department of Psychology, Columbia University, New York, NY, USA
}

Funding: This research was supported by grants R01 DA022541 (to KO) and K12 DA00167 (to HK) from the National Institute on Drug Abuse. These funding sources had no other role other

Acknowledgments: The authors would like to thank Peter Mende-Siedlecki and Katherine Remy for their help with early stages of implementation, and Chukwudi Onyemekwu, Steff Lyon, Daniel Bogart, Natalie Porter, Linh Tchang, and Colleen Doyle for their help with

Author contributions: K.O and H.K designed the study; R.L. and H.K. conducted analyses. The manuscript was written by R.L. and H.K, and edited by KO. The final manuscript was approved by all authors. The authors report no conflicts of interest.

In Press at The Journal of Substance Abuse Treatment.

Please cite this paper as: Lopez, R.B., Ochsner, K.N., \& Kober, H. (In Press). Brief training in regulation of craving reduces cigarette smoking. The Journal of Substance Abuse Treatment. 
Abstract

2 Craving is an important contributing factor in cigarette smoking and has been added as a

3 diagnostic criterion for addiction in the DSM-5. Cognitive-behavioral therapy and other

4 treatments that incorporate craving regulation strategies reduce smoking and likelihood of

5 relapse. Although this suggests that the regulation of craving is an important mechanism

6 underlying smoking cessation, it is unclear whether targeted interventions that train smokers to

7 regulate craving can directly impact real-world smoking behaviors. Across two pilot studies

$8(\mathrm{~N}=33 ; \mathrm{N}=60)$, we tested whether a brief, computer-delivered training session in the cognitive

9 regulation of craving altered subsequent smoking behaviors in daily life. Participants were first

10 randomly assigned to either a no training (control) group, or one of two Regulation of Craving

11 Training (ROC-T) conditions. Next, all participants came into the lab and those assigned to

12 ROC-T conditions were trained to implement a cognitive strategy to regulate their craving, by

13 either focusing on the negative consequences of smoking, or by distracting themselves. Then,

14 these participants underwent ROC-T during which they practiced using the strategy to regulate

15 their craving during cue exposure. Participants' smoking was subsequently assessed via daily

16 diaries for 3-6 days, and via self-report up to 1-month follow-up. Across both studies, ROC-T

17 conditions were associated with significant reductions in average cigarettes smoked per day, with

18 effects persisting through follow-up. These results confirm that the regulation of craving is an

19 important mechanism of smoking cessation, and can be targeted via easily administered training

20 procedures, such as ROC-T.

22 Keywords: Craving, regulation, smoking, computer-delivered training 
Cigarette smoking remains the most prevalent cause of preventable morbidity and

mortality in the world, including in the United States (Centers for Disease Control and Prevention (CDC), 2008). On average, smoking kills 1,200 Americans every day, accounting for 480,000 deaths per year (National Center for Chronic Disease Prevention and Health Promotion (US) Office on Smoking and Health, 2014), far exceeding deaths from AIDS, murders, suicide, car crashes, alcohol, and all illicit drugs_combined (Mokdad, Marks, Stroup, \& Gerberding, 2004). As far as morbidity, recent estimates indicate that approximately 14 million US adults had smoking-related medical conditions (Rostron, Chang, \& Pechacek, 2014). Moreover, smoking is associated with significant economic costs_ - including medical expenses and lost worker productivity - exceeding $\$ 289$ billion in the US alone (National Center for Chronic Disease Prevention and Health Promotion (US) Office on Smoking and Health, 2014). Finally, despite a marked declines in smoking rates over the past four decades (i.e., 42.4\% of US adults in 1965 to only $15.5 \%$ in 2016; Jamal et al., 2018), the coronavirus pandemic has halted this trend (North American Quitline Consortium, 2021; Rigotti et al., 2021) and smoking has been linked to increased severity of COVID-19 (Patanavanich \& Glantz, 2020; Purkayastha et al., 2020).

Importantly, smoking cessation rates remain low (Babb, Malarcher, Schauer, Asman, \& Jamal, 2017; Dutra et al., 2008), despite many smokers recognizing the harms of smoking and wanting to quit. Indeed, recent figures indicate that although $68 \%$ of smokers express the desire to quit every year, and $55.4 \%$ make an effort to quit, only $7.4 \%$ are successful (Babb et al., 2017). Why is quitting still an unattainable goal for so many smokers?

One important contributor to smoking is craving. Craving is defined in the DSM-5 as "a strong desire," and previously has been linked to smoking and relapse following quit attempts (Allen, Bade, Hatsukami, \& Center, 2008; Cooney et al., 2007; Doherty, Kinnunen, Militello, \& 
1 Garvey, 1995; Gass, Motschman, \& Tiffany, 2014; Shadel et al., 2011; Shiffman et al., 1997).

2 Further, craving that arises following exposure to smoking cues - known as cue-induced craving

3 - has also been reliably linked to smoking and relapse in particular studies (e.g., Carpenter et al.,

4 2009; Conklin et al., 2015; Waters et al., 2004) and across multiple studies in terms of robust

5 meta-analytic effects (Vafaie \& Kober, in revision). Indeed, this type of craving may be

6 especially important when considering treatment programs (Ferguson \& Shiffman, 2009).

7 Importantly, many models of addiction posit that the inability to exert control over cue-

8 induced craving underlies compulsive smoking and other drug-seeking behaviors (Everitt \&

9 Robbins, 2005; Goldstein \& Volkow, 2011; Koob \& Le Moal, 2001). As such, cue-induced

10 craving, and especially its regulation, might serve as an important target of smoking cessation

11 interventions to improve outcomes. Indeed, a key feature of cognitive-behavioral therapies

12 (CBT) for smoking cessation (and addiction more broadly) is to train individuals to change their

13 natural or prepotent responses (e.g., craving) to appetitive and/or affective stimuli by using

14 cognitive reappraisal strategies (e.g., considering their negative consequences). Further, use of

15 such strategies has been linked to reduced smoking in studies using ecological momentary

16 assessment (O’Connell, Hosein, Schwartz, \& Leibowitz, 2007).

17 We and others have tested whether such strategies effectively reduce craving in

18 controlled laboratory settings. For example, in a CBT-based regulation of craving (ROC) task,

19 cigarette-smoking participants were instructed to focus on the negative consequences of smoking

20 while being exposed to smoking cues, and reported a significant reduction in craving (Kober,

21 Kross, Mischel, Hart, \& Ochsner, 2010). Subsequent studies have replicated this result by

22 demonstrating that cigarette smokers can successfully implement this strategy via the ROC task

23 (Kober, Kross, et al., 2010; Luijten, van Meel, \& Franken, 2011), and that regulation success 
1 depends on the extent to which smokers recruit brain regions that were previously associated

2 with regulation of negative emotions (i.e., dorsolateral and ventrolateral prefrontal cortex; Buhle

3 et al., 2014; Kober, et al., 2010a). In turn, recruitment of these prefrontal regions was associated

4 with reduced activity in the ventral striatum and vmPFC (Kober et al., 2010b) — regions typically

5 linked to reward computation and the subjective experience of craving (e.g., see Diekhof, Kaps,

6 Falkai, \& Gruber, 2012 for a meta-analysis). This CBT-based ROC task has also been

7 administered to methamphetamine users, who successfully diminished their craving when

8 employing the regulation strategy described above (Lopez, Onyemekwu, Hart, Ochsner, \&

9 Kober, 2015). Similar findings have since been reported with other stimulant users, alcohol-

10 dependent individuals, and with food (Giuliani, Calcott, \& Berkman, 2013; Giuliani, Mann,

11 Tomiyama, \& Berkman, 2014; Naqvi et al., 2015; Suzuki et al., 2020; Volkow et al., 2010).

12 Another class of regulation strategies involves attentional deployment, which consists of

13 directing attention away from one's craving so it is not as intensely experienced and thereby

14 reduces the likelihood of someone indulging their craving. Indeed, such antecedent-focused

15 strategies are hypothesized to be effective because they intervene early before a craving is fully

16 expressed (Duckworth, Gendler, \& Gross, 2016), with some studies showing that smokers will

17 naturally use or favor attentional deployment (specifically distraction) over other strategies

18 (Hartwell et al., 2011). And although it is less frequently used in addiction treatment, distraction

19 is also part of CBT (Beck, 2011).

20 To build on these lines of work, we developed Regulation of Craving Training (ROC-

$21 \mathrm{~T}$ ) - a training procedure based on the ROC task, in which participants practiced using the above

22 strategies to regulate their craving over and over in the presence of cigarette cues. Here we tested

23 whether this brief, computerized training procedure is effective in reducing not only craving, but 
1 also cigarette smoking in daily life. Specifically, we conducted two pilot studies: we recruited

2 daily smokers who were motivated to reduce or quit smoking and randomly assigned them to one

3 of three groups: two experimental groups that received ROC-T and a control group that did not

4 receive an intervention. Both ROC-T conditions were CBT-based, with participants in one

5 condition trained to engage in cognitive reappraisal by focusing on the negative consequences of

6 smoking when experiencing craving, as described above. In the other ROC-T condition,

7 participants were trained to cognitively distract themselves by bringing to mind something

8 completely different when they feel craving. We included both strategies to test whether they

9 would be equally or differentially effective. Across both studies, participants completed ROC-T

10 via computer in the lab, and we measured their post-intervention craving and smoking behaviors

11 with daily diary surveys, an ecologically-valid and increasingly common way to assess

12 longitudinal changes in substance use behaviors (Roos, Kober, Trull, MacLean, \& Mun, 2020),

13 as well as follow-up telephone interviews.

14 Two primary hypotheses were tested in both studies, building on previous studies of the

15 efficacy of cognitive strategies in attenuating craving (e.g., Kober et al., 2010a; 2010b; Lopez et

16 al., 2015; Naqvi et al., 2015). We predicted that (1) participants in the Reappraisal-based ROC-T

17 and Distraction ROC-T groups would reduce their smoking relative to participants in the control

18 group; and (2) training in Reappraisal-based ROC would be more effective than training in

19 Distraction ROC. Accordingly, we specified a-priori contrasts that reflect these hypotheses in all

20 relevant statistical tests. 
Participants. Participants were recruited from the New York City area via flyers and postings on Craigslist.org. To be eligible, participants had to be $18-50$ years old, smoke every

3 day of the week, at least three cigarettes per day, and report being at least moderately motivated

4 to quit or reduce their smoking (i.e., $>4$ on a 1-7 likert scale). Participants were excluded if they

5 reported any current or past psychiatric and/or non-nicotine substance use disorders. Lastly, to

6 ensure compliance with the daily diary portion of the study, participants had to have reliable

7 internet access at home. If participants fulfilled all eligibility criteria, they were enrolled in the

8 study. After being screened by phone and deemed eligible, all participants gave informed

9 consent in accordance with the Institutional Review Board of Columbia University (under

10 approved protocol AAAC1363). Forty-six current cigarette smokers consented to participate in

11 the study and were randomized to one of the three experimental conditions. Of these participants,

12 six were no-shows for the first session and were not later reachable by email or phone, three did

13 not complete the baseline surveys, two did not complete the post-study surveys, one did not

14 come to the last study appointment, and one was found to be ineligible at a later time and was

15 excluded (due to rolling their own cigarettes). ${ }^{1}$ The final sample used for all subsequent analysis

16 consisted of 33 smokers (17 Female; $\left.\mathrm{M}_{\mathrm{age}}=27.8, \mathrm{SD}_{\mathrm{age}}=7.28\right)$. Of these participants, $50 \%$

17 identified as being White, 21.9\% as Black or African American, 9.4\% as Asian, Asian American,

18 or Pacific Islander, and $18.8 \%$ as Other/mixed race/unspecified; as far as ethnicity, $78.8 \%$

19 identified as non-Hispanic, and 21.2\% identified as Hispanic. Participants were randomly

20 assigned to the study's conditions as follows: Reappraisal-based ROC-T (N=11), Distraction-

\footnotetext{
${ }^{1}$ Although we provide information regarding retention and allocation for Study 1, we did not have all the information needed to generate a CONSORT diagram. However, we have included most items listed on the "CONSORT checklist when reporting a pilot or feasibility trial." For Study 2, we provide a CONSORT diagram (see Supplementary figure S1).
} 
1 based ROC-T ( $\mathrm{N}=11)$, and Control (no training; $\mathrm{N}=11)$. For all in-lab sessions, participants were

2 instructed to abstain from caffeine, food, and cigarettes for at least two hours.

3 Procedure. Study 1 had six major stages (see Figure 1 for schematic of study design): (1)

4 an initial session in the lab to acquire baseline cognitive and personality measurements (Day 1),

5 not reported here except the Ladder and Fagerström Test for Cigarette Dependence (FTCD;

6 Fagerström, 2011; Heatherton, Kozlowski, Frecker, \& Fagerström, 1991); (2) a pre-intervention

7 period in which participants completed daily diaries to assess smoking (cigarettes per day; Days

8 1-3); (3) a lab session that included surveys for all groups and ROC-T for the experimental

9 groups (Day 4); (4) a post-intervention sampling period of daily smoking behavior via daily

10 diaries (Days 4-7); (5) a final lab session with personality and cognitive task measures (Day 8);

11 and (6) One and two-week follow-up assessments of smoking behavior, administered by phone.

12 Pre-intervention period. For the initial lab session (Day 1), participants completed the

13 FTCD as well as a battery of cognitive tasks and individual difference questionnaires (which are

14 not relevant to the present hypotheses, and may be reported elsewhere). For the following three

15 days (Days 1-3), to establish a baseline, participants completed online daily diaries within 30

16 minutes of going to bed and were asked the following questions: "How many times did you

17 crave cigarettes today?"; "How many cigarettes did you smoke today?"; "Did you buy a new

18 pack?"; and "Did you encounter situations that may have triggered craving?"

19 ROC-T Lab Session. Next, on Day 4 all participants came back to the lab and completed

20 laboratory and questionnaire measures (not reported here). At this point, the lab session ended

21 for participants in the control condition, but participants in the intervention conditions continued

22 on to the training stage of the session. 
For training, participants first read either an essay detailing the negative consequences

2 associated with smoking (Reappraisal-based ROC-T) or an essay about the history of tobacco in

3 the United States (Distraction-based ROC-T; see Supplementary Materials). Participants then

4 performed a memory recall task to ensure they adequately remembered 10 facts from the essays

5 (e.g., "over 400,000 people die each year from smoking related illnesses", or "70\% of Burley

6 tobacco comes from Kentucky"). If they did not have a 100\% score on the recall task, they were

7 given additional attempts to respond (after re-reading the essay), and were re-tested until they

8 achieved a $100 \%$ score.

9 Next, participants read a statement in which they were reminded of their goal to reduce

10 and/or quit smoking for the following week and were instructed to formulate a specific plan

11 consistent with their goal (e.g., "I will smoke X fewer cigarettes a day for the next week"). Once

12 they indicated their plan, they were given a strategy by which they could implement their plan by

13 first generating 10 situations or cues that was likely to induce craving to smoke on a daily basis

14 (e.g., "When I have my morning cup of coffee"). Based on these self-generated situations or

15 cues, participants generated "if-then" implementation intentions (adapted from Gollwitzer, 1999)

16 and were instructed to focus on recalling the essay material (see Supplementary Material). For

17 example, a participant might generate the statement, "If I experience craving when having my

18 morning cup of coffee, I will think about (1) the negative consequences of smoking (if in

19 Reappraisal-based ROC-T condition); or (2) historical facts about tobacco (if in Distraction-

20 based ROC-T condition)." After specifying these implementation intentions, and stating they

21 understood the overall strategy, participants completed a training block of trials in which they

22 imagined the craving-inducing situations they previously identified and practiced implementing

23 the strategy. Next, to train them to use the strategy in moments of craving, we administered 
1 ROC-T, which we adapted from our prior work (Kober et al., 2010a; 2010b). On each trial

2 during the task, the word "LOOK" or "STRATEGY" would appear on the screen, followed by

3 an appetitive smoking cue (e.g., a lit cigarette in an ashtray), then a rating scale that ranged from

41 (not at all) to 5 (very much) for participants to indicate their cue-induced craving on that trial.

5 On "LOOK" trials, participants were instructed to just respond naturally to the subsequent

6 smoking. On "STRATEGY" trials, participants were prompted to implement the strategy (i.e.,

7 either "think about the negative consequences of smoking" or "think about historical facts about

8 tobacco") when the smoking cue was on the screen. In total, ROC-T included 50 trials, with 25

9 "LOOK" trials and 25 "STRATEGY" trials (instruction-cue pairings randomized for each

10 participant).

11 Post-intervention and follow-up periods. On the night of the in-lab intervention session

12 (Day 4), participants completed a daily diary in which they were asked to report the time of the

13 first cigarette they smoked after leaving the lab, and how many cigarettes they craved and

14 smoked across several blocks of time between leaving the lab and when they started the daily

15 diary. Next, for the post-intervention sampling period (Days 4-7), participants responded to

16 online daily diaries each night before going to bed. All questions were the same as the pre-

17 intervention diaries, with the only difference being that the Reappraisal-based and Distraction

18 ROC-T groups answered questions about how successful they were in implementing the strategy.

19 On Day 8, all participants returned to the lab for post-intervention measurements of

20 smoking urges and cigarette attitudes (assessed via questionnaires), and as well as other

21 behavioral tasks and individual difference questionnaires (not reported). Lastly, follow-up

22 assessments of daily smoking, conducted via phone interview, occurred 1 week and 2 weeks

23 following the final (Day 8) lab session for all groups (ROC-T groups and control group). For 
1 each follow-up interview, participants were asked "How many cigarettes are you smoking, on

2 average, each day?" Overall, responses rates for the daily dairies and follow-up assessments

3 were high, ranging from $88 \%$ to $100 \%$.

$4 \quad$ Results

5 We observed no group-level baseline differences in age, gender, Ladder scores, FTCD

6 scores, or pre-study cigarettes smoked per day, all $p$ 's $\geq .08$ (see Table 1), and differences in

7 participants' education level are reported in the Supplementary Analyses. To assess whether

8 there were overall changes in cigarettes smoked per day (CPD) throughout the study's

9 measurement periods, and whether there were time-by-group interactions, we ran a mixed, 3-by-

104 repeated-measures ANOVA, with group (Control, Reappraisal-based ROC-T, and Distraction

11 ROC-T) as a between-subjects factor, and time (Pre-intervention, Post-Intervention, 1-week

12 follow-up, 2-week follow-up) as the within-subjects factor. There was a significant main effect

13 of time on $\operatorname{CPD}\left(F_{(3,78)}=2.88, \eta^{2}\right.$ partial $\left.=.10, p=.042\right)$, which was qualified by a significant

14 group-by-time interaction $\left(F_{(6,78)}=2.37, \eta^{2}\right.$ partial $\left.=.15, p=.037\right)$. The nature of this interaction

15 was clarified in a significant linear contrast for the interaction $\left(F_{(2,26)}=3.41, \eta^{2}\right.$ partial $=.21, p$

$16=.048)$. Specifically, the Reappraisal-based ROC-T group showed sustained reduction in CPD

17 over time, while the Distraction ROC-T group had an initial reduction, and the Control group

18 showed little to no change in CPD over the study timeline (see Figure 2). In terms of percentage

19 reductions in cigarettes smoked per day (compared to participants' pre-intervention levels), the

20 Reappraisal-based ROC-T group reported reductions ranging between $22-49 \%$ across the post-

21 intervention assessment and one- and two-week follow-ups, and the Distraction ROC-T group

22 reported reductions of $26-36 \%$.

\section{Study 2}


The motivation for Study 2 was to replicate the findings from Study 1 in a larger sample

2 of smokers and to test whether ROC training would be effective for relatively heavier smokers.

3 Method

$4 \quad$ A priori power analysis. To guide sample size planning and stopping rules for Study 2,

5 we used the effect size of the interaction term in Study $1\left(\eta^{2}\right.$ partial $\left.=.15\right)$ and conducted power

6 analyses with G*Power (Faul, Erdfelder, Lang, \& Buchner, 2007), assuming 90\% power and a

7 range of small-to-medium effect sizes for a repeated measures ANOVA with a within-between

8 interaction effect (time was indicated as the within-subjects factor with 5 levels and

9 group/training status was indicated as the between-subjects factor with 3 levels). The required

10 total sample size ranged from 40-70, but we wanted to be able to detect smaller effects, so we

11 aimed to have approximately 20-25 participants per condition.

12 Participants. For Study 2, screening and inclusion criteria were identical to those for

13 Study 1 (see above), except that respondents had to report smoking at least eight cigarettes a day,

14 seven days a week to be eligible to participate. This was done to determine if the training would

15 also benefit relatively heavier smokers. So, we recruited a new, independent sample of ninety-

16 five eligible participants from the New York City area via flyers and online Craigslist postings.

17 All participants completed an online consent form and were then randomly assigned to one of the

18 three conditions (Reappraisal- or Distraction-based ROC-T, or Control/No Training). Of these,

19 eighty-one began study assessments (i.e., initial daily diaries) and of these, 60 participants (28

20 Female) continued with the rest of the study through its completion, leaving a final $\mathrm{N}$ of 60 for

21 all reported analyses (see Supplementary figure S1 for CONSORT diagram). Among these

22 participants $\left(\mathrm{M}_{\mathrm{age}}=37.35, \mathrm{SD}_{\mathrm{age}}=9.39\right)$, there were 28 Females, and $44.1 \%$ identified as being

23 White, 25.4\% as Black or African American, 10.2\% as Asian, Asian American, or Pacific 
1 Islander, $1.7 \%$ as Native American, and $18.8 \%$ as Other/mixed race/unspecified; as far as

2 ethnicity, $72.9 \%$ identified as non-Hispanic, and $27.1 \%$ identified as Hispanic. These participants

3 were randomly assigned to the study conditions as follows: Reappraisal-based ROC-T $(\mathrm{N}=21)$,

4 Distraction-based ROC-T ( $\mathrm{N}=18)$, and Control (no training; $\mathrm{N}=21)$. For all in-lab sessions,

5 participants were instructed to abstain from caffeine, food, and cigarettes for at least two hours.

6 Procedure. Study 2 followed Study 1's procedure closely. However, in order to

7 streamline the study design and increase compliance over the study's timeline, we enacted the

8 following changes: participants in Study 2 did not come in for an initial lab session and there

9 were fewer tasks administered during lab sessions. Further, to assess whether the effects of ROC-

10 T were robust and longer lasting (compared to Study 1), the post-intervention daily diary

11 sampling period was extended to seven days, and there was an additional follow-up timepoint at

12 one month. Participants were also randomly assigned to group at the outset of the study (after

13 consent), so only the experimental (Reappraisal-based and Distraction ROC) groups came in to

14 the lab to complete the lab session. Accordingly, Study 2 had five stages (see Figure 3 for

15 schematic): (1) An initial, pre-intervention period in which participants completed daily diaries

16 to assess smoking (as in Study 1; Days 1 -3); (2) An in-lab session in which we assessed

17 baselines levels of nicotine dependence (indexed by the FTCD), administered ROC-T for both

18 active groups, as well as other individual difference measures (not described here; Day 4); (3) A

19 post-intervention sampling period of smoking behavior via daily diaries for one week (Days 4 -

20 10); (4) A final in-lab session in which we re-administered some measures (not described here;

21 Day 11); and (5) Follow-up phone surveys, administered at 1-week, 2-week, and 1-month post-

22 intervention, in which participants reported their levels of daily smoking. All other procedural

23 details, survey questions, and task protocols of these five stages were identical to those in Study 
11 (see above). As in Study 1, responses rates for the daily dairies and follow-up assessments

2 were high, ranging from $72 \%$ to $100 \%$ across all assessment periods, with the lowest response

3 rates (i.e., $72 \%$ and $83 \%$ ) taking place at the longer-term follow ups.

4 Results

As in Study 1, there were no group differences in age, gender, Ladder scores, FTCD

6 scores, or pre-study mean CPD (all $p$ 's $\geq .39$; see Table 2), and differences in participants'

7 education level are again reported in the Supplementary Analyses. To test for whether effects

8 from Study 1 replicated in Study 2, we subjected the data to a mixed 3-by-5 repeated-measures

9 ANOVA with group (Control, Reappraisal-based ROC-T, Distraction ROC-T) as the between-

10 subjects factor and time (Pre-intervention, Post-intervention, and 1-week, 2-week, and 1-month

11 follow-up) as the within-subjects factor. Sphericity in the variance-covariance structure was

12 violated (Mauchly's $W=0.42, p=.001$ ), so we used the Greenhouse-Geisser correction with

13 adjusted degrees of freedom. There was a significant main effect of time on $\operatorname{CPD}\left(F_{(2.62,91.70)}=\right.$

$1415.14, \eta^{2}$ partial $\left.=.30, p<.001\right)$, which was qualified by a significant group-by-time interaction

$15\left(F_{(5.24,91.70)}=4.46, \eta^{2}\right.$ partial $\left.=.20, p=.001\right)$. The nature of this interaction was clarified in a

16 significant linear contrast for the interaction term $\left(F_{(2,35)}=7.26, \eta^{2}\right.$ partial $\left.=.29, p=.002\right)$, and a

17 significant linear trend overall $\left(F_{(1,35)}=23.20, \eta^{2}\right.$ partial $\left.=.40, p<.001\right)$. In this case, there were

18 sustained reductions in CPD in both Reappraisal-based and Distraction ROC-T groups, while

19 CPD in the Control group was relatively flat throughout (see Figure 4 for a visual depiction of

20 these effects). Lastly, in terms of percentage reductions in cigarettes smoked per day, the

21 Reappraisal-based ROC-T group reported reductions ranging between $29-39 \%$ across the post-

22 intervention and follow-up assessments, and the Distraction ROC-T group reported reductions of $23 \quad 30-47 \%$. 


\section{Discussion}

The primary goal of the present studies was to assess whether ROC-T - brief training in

3 CBT-based cognitive strategies targeting regulation of craving - would effectively reduce

4 cigarette smoking in daily life. Specifically, we hypothesized that participants in the

5 experimental ROC-T groups (Reappraisal-based ROC-T and Distraction ROC-T groups) would

6 experience significantly lower craving and smoke less than participants in the control group, and

7 that training in Reappraisal-based ROC-T (vs. Distraction ROC-T) would be most efficacious.

8 Across both studies, and in support of our first hypothesis, smokers who underwent ROC-T-

9 either Reappraisal-based or Distraction-based - successfully reduced their real-world smoking

10 (compared to control groups), and this persisted for 2 weeks (Study 1) and 1 month (Study 2)

11 post-intervention. Importantly, this pattern of results was obtained across two independent

12 samples that consisted of relatively lighter (Study 1) and heavier (Study 2) smokers, respectively.

13 These results suggest that a brief, single-session training that targets the regulation of craving

14 using CBT-based principles is effective for smoking reduction, at least in the short term.

15 Interestingly, we did not find support for our second primary hypothesis, that

16 Reappraisal-based ROC-T would be more effective in reducing smoking than Distraction ROC-

17 T. The finding that both ROC strategies equivalently reduced craving suggests they may share

18 some common mechanism, such as controlling the deployment of attention. For the Reappraisal-

19 based ROC-T group, this meant directing attention toward the negative consequences of the

20 craved item (i.e., cigarette), and for the Distraction ROC-T group, this meant directing attention

21 toward unrelated, neutral content (i.e., the history of tobacco) tangential to the act of smoking. In

22 either case, participants could redirect their attention and therefore avoid experiencing the full

23 intensity of craving they would otherwise experience. This interpretation is consistent with 
1 process models of emotion and craving regulation, which posit that antecedent-focused

2 strategies, such as attentional (re)deployment, are particularly effective because they can be

3 implemented relatively early on in the emotion/craving generation process (Duckworth, Gendler,

4 \& Gross, 2016; Gross, 2002). Nevertheless, despite the similar reduction in smoking across

5 reappraisal- and distraction-based ROC-T, it is also likely that the two strategies have some

6 distinct mechanisms as well. For example, reappraisal-based ROC-T may alter the subjective

7 valuation of smoking (Berkman, Hutcherson, Livingston, Kahn, \& Inzlicht, 2017; Sun \& Kober, 8 2020).

9 Overall, these findings suggest that successful implementation of ROC strategies can

10 mitigate the known effects of cue exposure (e.g., Kober, Turza, \& Hart, 2009) and cue-induced

11 craving (e.g., Ferguson \& Shiffman, 2009) on smoking and relapse. The present results are

12 consistent with previous work demonstrating that smokers can successfully regulate their

13 cravings using a CBT-based ROC strategy (Kober et al., 2010a) and the neural mechanisms

14 supporting such regulation (see Kober et al., 2010b). More recently, we followed up on the

15 current study (which was yet unpublished) and showed that ROC-T in the eating domain

16 promotes healthier food choices and reduces caloric consumption (Boswell, Sun, Suzuki, \&

17 Kober, 2018). Individual differences in implementation success of a ROC strategy also have

18 been linked to healthier eating patterns in daily life, as measured by ecological momentary

19 assessment (Reader, Lopez, \& Denny, 2018).

20 Importantly, ROC-T in the present studies and other cited work is domain-specific, as it

21 targets cue-induced craving in a particular domain (e.g., smoking, eating), and therefore avoids

22 the issues associated with domain-general training, such as limited transfer effects (e.g.,

23 Beauchamp, Kahn, \& Berkman, 2016). Others have taken a similar approach with positive 
1 results, such as Chen and colleagues (2018) who showed that domain-specific, food-cue

2 inhibitory training (versus domain-general training) was effective in reducing the strength of

3 daily food cravings in dieters (Chen, Kelley, Lopez, \& Heatherton, 2018).

4 The present findings also highlight the promise of applying CBT-based ROC strategies as

5 a brief, targeted, computerized, mechanism-focused intervention to reduce smoking. This is

6 consistent with prior clinical work on coping skills, which are often a key component of CBT

7 and involve strategies that help patients better understand their cravings and avoid particular

8 triggers that elicit such craving for the desired substance. Coping skills training has been shown

9 to predict long-term abstinence for marijuana dependence (Litt, Kadden, Kabela-Cormier, \&

10 Petry, 2008), and coping skill acquisition and development, as part of CBT, has been associated

11 with reduced drinking and increased abstinence among those with alcohol abuse or dependence

12 (Litt, Kadden, Cooney, \& Kabela, 2003). In another study of individuals seeking treatment for

13 substance use disorders, quality of coping responses during CBT mediated treatment success to

14 predict greater abstinence up to three-months post-treatment (Kiluk, Nich, Babuscio, \& Carroll,

15 2010). This suggests that a particularly effective component of coping strategies administered in

16 CBT may be the regulation of cue-induced craving, so clinicians may want to consider explicitly

17 incorporating personalized ROC strategies (as operationalized here) into daily or weekly CBT

18 homework to promote reduction of craving and abstinence over time.

As an intervention, ROC-T has the distinct advantage of being theory-based and

20 mechanism-focused, specifically around craving and the regulation of craving, both core

21 processes long thought to be central to addictions in general and cigarette smoking in particular.

22 Indeed, a theory-driven focus on core mechanisms can facilitate development, testing, and

23 refinement of interventions, leading to better efficacy, effectiveness, and efficiency (e.g., Naqvi 
1 \& Morgenstern, 2015; Onken, Carroll, Shoham, Cuthbert, \& Riddle, 2014). Indeed, a focus on

2 mechanisms can facilitate precision-based delivery of interventions for substance use (including

3 smoking) in the real-world, via monitoring of changes in the targeted mechanism at

4 symptomatic, cognitive, and neural levels (including changes that may occur before symptom

5 change). It can also ultimately facilitate matching of interventions to specific subpopulations

6 (Onken et al., 2014; Witkiewitz, Roos, Mann, \& Kranzler, 2019). Further, ROC-T has the

7 distinct advantage of being fully computerized, and thus easy to implement, test, and

8 disseminate, including as a web-based intervention. This is important as technology-based

9 interventions have the potential to greatly expand the reach of evidence-based treatments (e.g.,

10 Price et al., 2014; Schueller \& Torous, 2020) and have been shown to be viable, effective, and

11 cost-effective for a wide range of disorders, including SUDs (e.g., Carroll \& Kiluk, 2017;

12 Marsch, Carroll, \& Kiluk, 2014).

13 Despite the promise of the present findings and their implications for smoking cessation

14 treatment, there are some limitations that are worth mentioning. First, although daily diary

15 measures are a valid and often preferred method to capture daily substance use behaviors in vivo

16 (Roos et al., 2020), our main outcome measure (cigarettes smoked per day) was nonetheless

17 estimated from self-report. Future studies can and should incorporate additional validation of

18 smoking (e.g., via carbon monoxide or urine cotinine measures) - which is now our practice as

19 well (Kober, Brewer, Height, \& Sinha, 2017). Second, despite consistent effects observed across

20 the two studies, sample sizes (especially in Study 1) were low, so the design used in the present

21 work should be applied to new, larger samples and the effects should be tested and replicated in

22 those samples, in randomized-controlled clinical trials. 
Another limiting factor, as far as the generalizability of the results, is that we only

2 recruited from a subset of the smoking population. That is, those smokers who were already

3 somewhat motivated to reduce or quit smoking. Previous work has highlighted the benefits of

4 autonomous motivation (i.e., personally valuing and "owning" behavior change goals), versus

5 controlled motivation (i.e., goal pursuit due to externally imposed demands), for various self-

6 regulatory behaviors, including healthy eating (Pelletier, Dion, \& Slovinec-D'Angelo, 2004),

7 diabetes management (Senécal, Nouwen, \& White, 2000), and even smoking cessation

8 (Williams, Gagné, Ryan, \& Deci, 2002). Therefore, it is possible that ROC strategies may only

9 be effective for those smokers who are intrinsically/autonomously motivated to change their

10 behavior in the first place. Future studies will need to examine this possibility by specifically

11 comparing effects of ROC-T on smoking cessation outcomes as a function of autonomous

12 (versus controlled) motivation. Moreover, since we did not assess participants' long-term

13 abstinence outcomes, it is not clear whether ROC-T leads to sustained and lasting smoking

14 reduction or abstinence on its own. If not, perhaps this kind of training can be paired with other

15 treatments to ensure long-term reductions in smoking and eventual quitting. Lastly, the education

16 level of participants was relatively high, as most were college-educated or had some

17 postgraduate training (see tables in Supplementary Materials), so future studies will also need to

18 test for generalizability across a wider range of education levels. We also recommend that future

19 intervention studies specifically test for moderation effects, as the efficacy of ROC-T

20 generally — or reappraisal or distraction strategies in particular - may vary based on gender,

21 nicotine dependence, baseline craving, and other factors. Future work should also assess the

22 potential benefits of joint training in both reappraisal-based ROC-T and distraction-based ROC- 
$1 \mathrm{~T}$, as this would give individuals additional strategies that they could flexibly deploy across real

2 world contexts that elicit craving.

3 To conclude, we have demonstrated that a brief, 45-minute training session in regulation

4 of craving can impact real world smoking levels. Our findings also demonstrate ecological

5 validity of laboratory-based cognitive strategy training, as applied to regulating smoking

6 behaviors in the wild and across idiosyncratic cues and contexts across participants. And despite

7 the caveats described above, we believe that an approach like the one utilized here can help

8 scientists and clinicians alike develop relatively easy-to-administer smoking cessation protocols

9 to help cigarette smokers achieve their goals to reduce smoking or quit altogether. 
2

3

4

\begin{tabular}{|lcccccc|}
\hline & $\begin{array}{c}\text { Mean age } \\
\text { (SD) }\end{array}$ & Male & Female & $\begin{array}{c}\text { Mean } \\
\text { Ladder (SD) }\end{array}$ & $\begin{array}{c}\text { Mean } \\
\text { FTCD (SD) }\end{array}$ & $\begin{array}{c}\text { Pre-study } \\
\text { CPD (SD) }\end{array}$ \\
\hline Control (11) & $27.82(8.42)$ & 6 & 5 & $6.27(1.68)$ & $4.09(1.92)$ & $11.68(6.44)$ \\
\hline $\begin{array}{l}\text { Reappraisal-based } \\
\text { ROC-T (11) }\end{array}$ & $24.64(5.85)$ & 6 & 5 & $8.00(1.48)$ & $5.09(1.81)$ & $9.59(4.75)$ \\
\hline $\begin{array}{l}\text { Distraction ROC-T } \\
(11)\end{array}$ & $31.09(6.44)$ & 4 & 7 & $7.09(2.02)$ & $4.82(1.78)$ & $11.64(7.60)$ \\
\hline
\end{tabular}

5

6

7

8

9

10

11

12

13

14

15

16

17

18

19

20

21

22

23

24

25

26

27

28

29

30

31

32

33

34

\section{Tables \& Figures}

Table 1. Demographics for the Study 1 Sample $(\mathrm{N}=33)$.

\section{(}

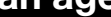

Group (N)

(SD)

Male Female

FCD (SD)

CPD (SD)

Reappraisal-based

Distraction ROC-T

(11)

8

(1)

1

12

(1)

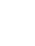

(8)

(1)

(n)

4

(1)

(2)

(29


1

2

\begin{tabular}{|lcccccc|}
\hline Group (N) & $\begin{array}{c}\text { Mean age } \\
\text { (SD) }\end{array}$ & Male & Female & $\begin{array}{c}\text { Mean } \\
\text { Ladder } \\
\text { (SD) }\end{array}$ & $\begin{array}{c}\text { Mean } \\
\text { FTCD (SD) }\end{array}$ & $\begin{array}{c}\text { Pre-study } \\
\text { CPD (SD) }\end{array}$ \\
\hline Control (21) & $38.00(10.52)$ & 10 & 11 & $7.42(2.76)$ & $5.34(2.38)$ & $18.17(7.77)$ \\
\hline $\begin{array}{l}\text { Reappraisal-based } \\
\text { ROC-T (21) }\end{array}$ & $35.14(9.25)$ & 13 & 8 & $8.00(1.84)$ & $4.90(2.55)$ & $15.91(8.05)$ \\
\hline $\begin{array}{l}\text { Distraction ROC-T } \\
(18)\end{array}$ & $39.17(8.07)$ & 9 & 9 & $8.00(2.20)$ & $5.08(1.75)$ & $18.53(7.68)$ \\
\hline
\end{tabular}

Table 2. Demographics for the Study 2 Sample $(\mathrm{N}=60)$.

3

4

5

6 
Baseline / pre-intervention period
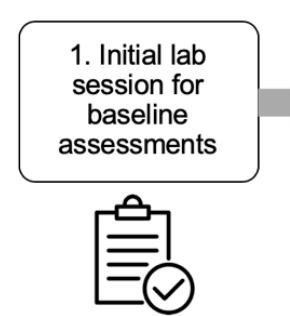

2. Three-day assessment of daily smoking behaviors

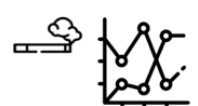

\section{Intervention}
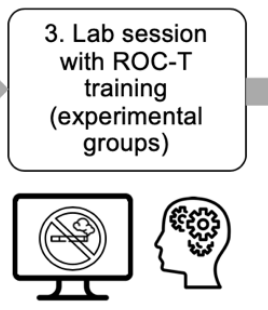

1

Figure 1. Schematic of study design for Study 1, which consisted of the following components and assessment periods: (1) an initial session in the lab to acquire baseline cognitive and personality measurements (Day 1); (2) a pre-intervention period in which participants completed daily diaries to assess smoking (cigarettes per day; Days 1-3); (3) a lab session that included surveys for all groups and ROC-T for the experimental groups (Day 4); (4) a post-intervention sampling period of daily smoking behavior via daily diaries (Days 4-7); (5) a final lab session with personality and cognitive task measures (Day 8); and (6) One and two-week follow-up assessments of smoking behavior, administered by phone. 


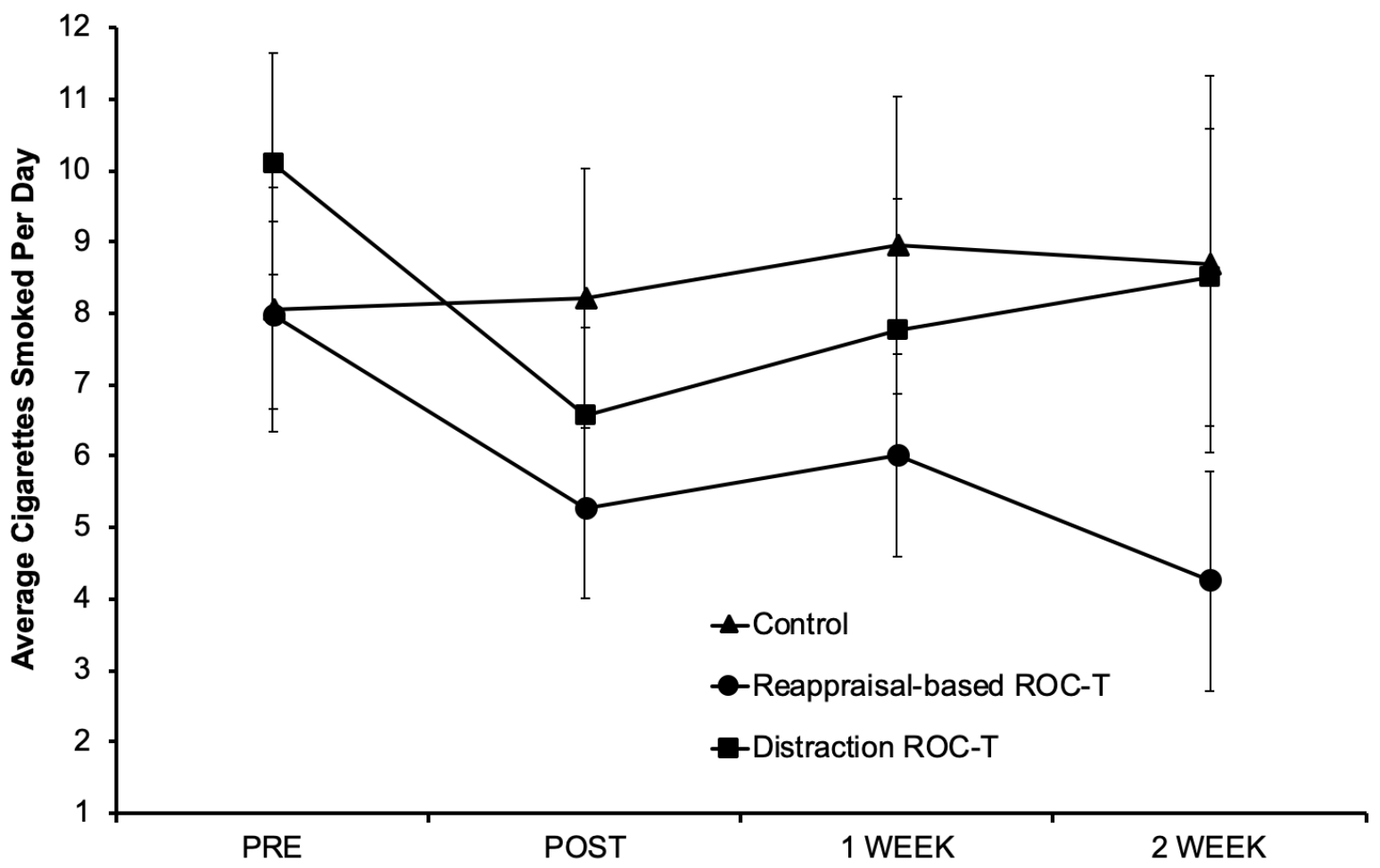

Figure 2. Average cigarettes smoked per day by group (indicated by line type), across Study 1's 3 assessment periods (error bars indicate \pm SEM). 


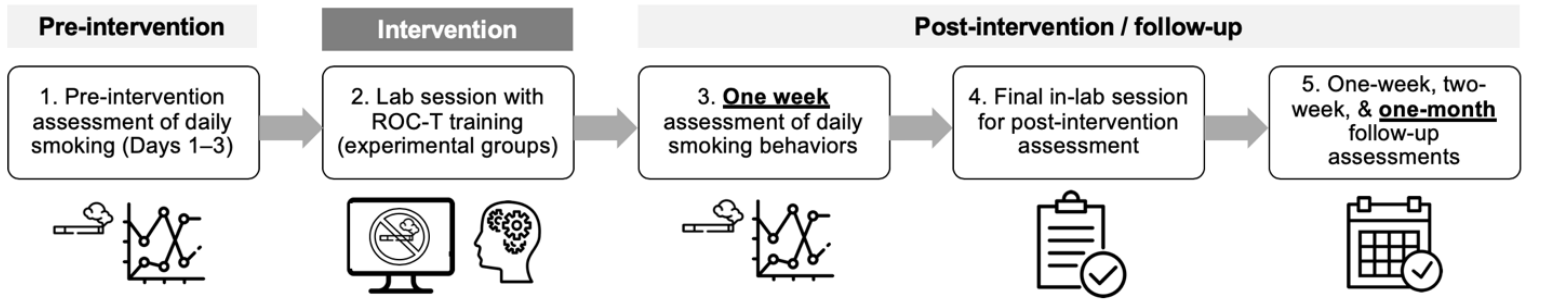

Figure 3. Schematic of study design for Study 2, which consisted of the following components and assessment periods: (1) An initial, pre-intervention period in which participants completed daily diaries to assess smoking (as in Study 1; Days 1 - 3); (2) An in-lab session in which we administered ROC-T for both active groups, as well as other measures (not described here; Day 4); (3) A post-intervention sampling period of smoking behavior via daily diaries for one week (Days 4 - 10); (4) A final in-lab session in which we re-administered some measures (not described here; Day 11); and (5) Follow-up phone surveys, administered at 1-week, 2-week, and 1-month post-intervention, in which participants reported their levels of daily smoking. 


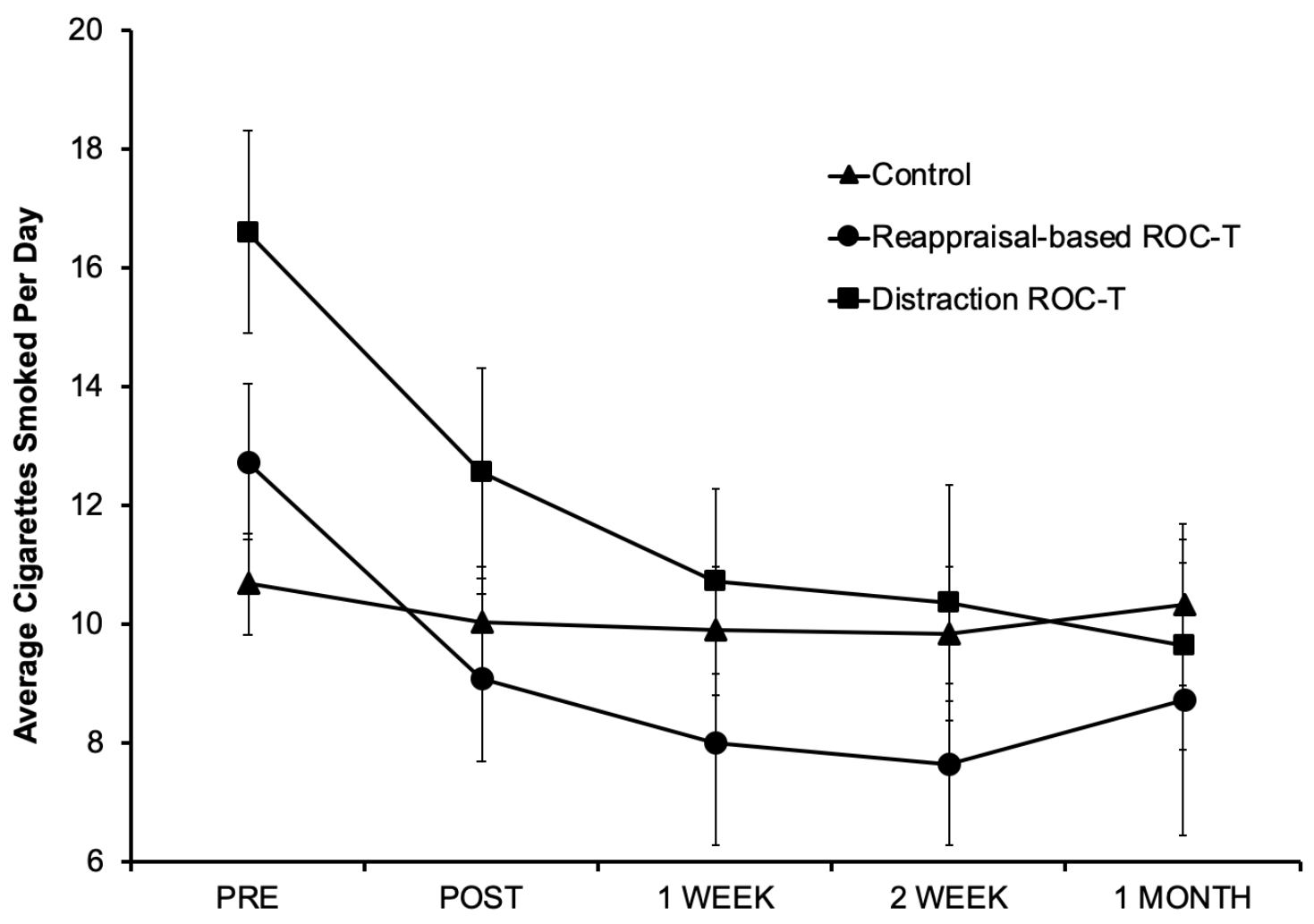

Figure 4. Average cigarettes smoked per day by group (indicated by line type), across Study 2's assessment periods (error bars indicate $\pm \mathrm{SEM}$ ). 


\begin{tabular}{llll}
\hline Level & & Count & Proportion \\
\hline HS & Observed & 1 & 0.0370 \\
& Expected & 9.00 & 0.333 \\
Postbac/grad & Observed & 10 & 0.3704 \\
& Expected & 9.00 & 0.333 \\
Some college/in progress & Observed & 16 & 0.5926 \\
& Expected & 9.00 & 0.333 \\
\hline
\end{tabular}

7

$\chi^{2}$ Goodness of Fit

\begin{tabular}{lll}
$\boldsymbol{\chi}^{\mathbf{2}}$ & $\mathbf{d f}$ & $\mathbf{p}$ \\
\hline 12.7 & 2 & 0.002 \\
\hline
\end{tabular}

8

9 Counts by group

\begin{tabular}{lllll} 
Group & HS & Postbac/grad & Some college/in progress & Total \\
\hline Control & 1 & 0 & 9 & 10 \\
Health & 0 & 5 & 5 & 10 \\
Neutral & 0 & 5 & 2 & 7 \\
Total & 1 & 10 & 16 & 27 \\
\hline
\end{tabular}

$\chi^{2}$ Tests

\begin{tabular}{llll} 
& Value & df & $\mathbf{p}$ \\
\hline$\chi^{2}$ & 10.9 & 4 & 0.027 \\
$\mathrm{~N}$ & 27 & & \\
\hline
\end{tabular}


1 Frequencies and chi-square tests for participants' education level (Study 2)

2

\begin{tabular}{llll}
\hline Level & & Count & Proportion \\
\hline HS & Observed & 6 & 0.143 \\
& Expected & 14.0 & 0.333 \\
Postbac/grad & Observed & 19 & 0.452 \\
& Expected & 14.0 & 0.333 \\
Some college/in progress & Observed & 17 & 0.405 \\
& Expected & 14.0 & 0.333 \\
\hline
\end{tabular}

3

$\chi^{2}$ Goodness of Fit

\begin{tabular}{lll}
$\boldsymbol{\chi}^{\mathbf{2}}$ & $\mathbf{d f}$ & $\mathbf{p}$ \\
\hline 7.00 & 2 & 0.030 \\
\hline
\end{tabular}

4

5 Counts by group

\begin{tabular}{lllll} 
Group & HS & Postbac/grad & Some college/in progress & Total \\
\hline Control & 2 & 6 & 8 & 16 \\
Health & 1 & 7 & 4 & 12 \\
Neutral & 3 & 6 & 5 & 14 \\
Total & 6 & 19 & 17 & 42 \\
\hline
\end{tabular}

6

$\chi^{2}$ Tests

\begin{tabular}{llll} 
& Value & df & $\mathbf{p}$ \\
\hline$\chi^{2}$ & 2.11 & 4 & 0.716 \\
$\mathrm{~N}$ & 42 & & \\
\hline
\end{tabular}


1 Tests for differences in cigarettes smoked per day (at screening) and motivation to reduce and

2 quit between participants who completed and did not complete the study (Study 2)

For Study 2, screening information for participants who did not finish the study was incomplete, but for a subgroup for whom we did have complete screening data $(\mathrm{N}=16)$, we conducted three independent samples t-tests to test for potential differences in cigarettes smoked per day (at time of screening), motivation to reduce, and motivation to quit. Given the unequal sample sizes $(\mathrm{N}=16$ and $\mathrm{N}=60)$, we tested whether the assumption of homogeneity of variance was violated in these cases, but it was not for any of the tests, all $p$ 's $\geq .252$. The t-tests revealed that there was no significant difference in cigarettes smoked per day, $t(74)=0.48, p=.64$, motivation to reduce smoking, $t(74)=0.42, p=.67$, or motivation to quit smoking, $t(74)=0.67$, $p=.51$

Results and discussion from mixed ANOVAs with craving instances as the outcome measure For Study 1 and Study 2, we ran mixed ANOVAs with craving instances as the outcome measure. For both studies, there was a significant main effect of time, $p$ 's $\leq .007$, and no significant group-by-time interaction, $p$ 's $\geq .112$. However, as an exploratory analysis to assess within-group changes in craving, we carried post-hoc pairwise comparisons with Tukey's correction for multiple tests. We found that for the Distraction ROC-T group, there was a significant decrease in craving for the post-intervention, compared to the pre-intervention period; this was true for Study $1, t(27)=3.45, p_{\text {tukey }}=.02$, and for Study $2, t(56)=3.50, p_{\text {tukey }}=.01$.

Although this result came out of an exploratory analysis, it provides preliminary evidence that Distraction ROC-T may more directly target craving as to whether it is experienced or not in the first place, a plausible mechanism given that it is a regulatory strategy that intervenes earlier in the impulse-generation process, as per the process model of emotion regulation (Duckworth et 
1 al., 2016). This pattern was not observed in the Reappraisal ROC-T group(s), which is not

2 surprising since our measure of craving frequency was relatively coarse and did not get at the

3 nature or intensity of the experienced craving, which presumably would be affected by

4 reappraisal.

5

6 


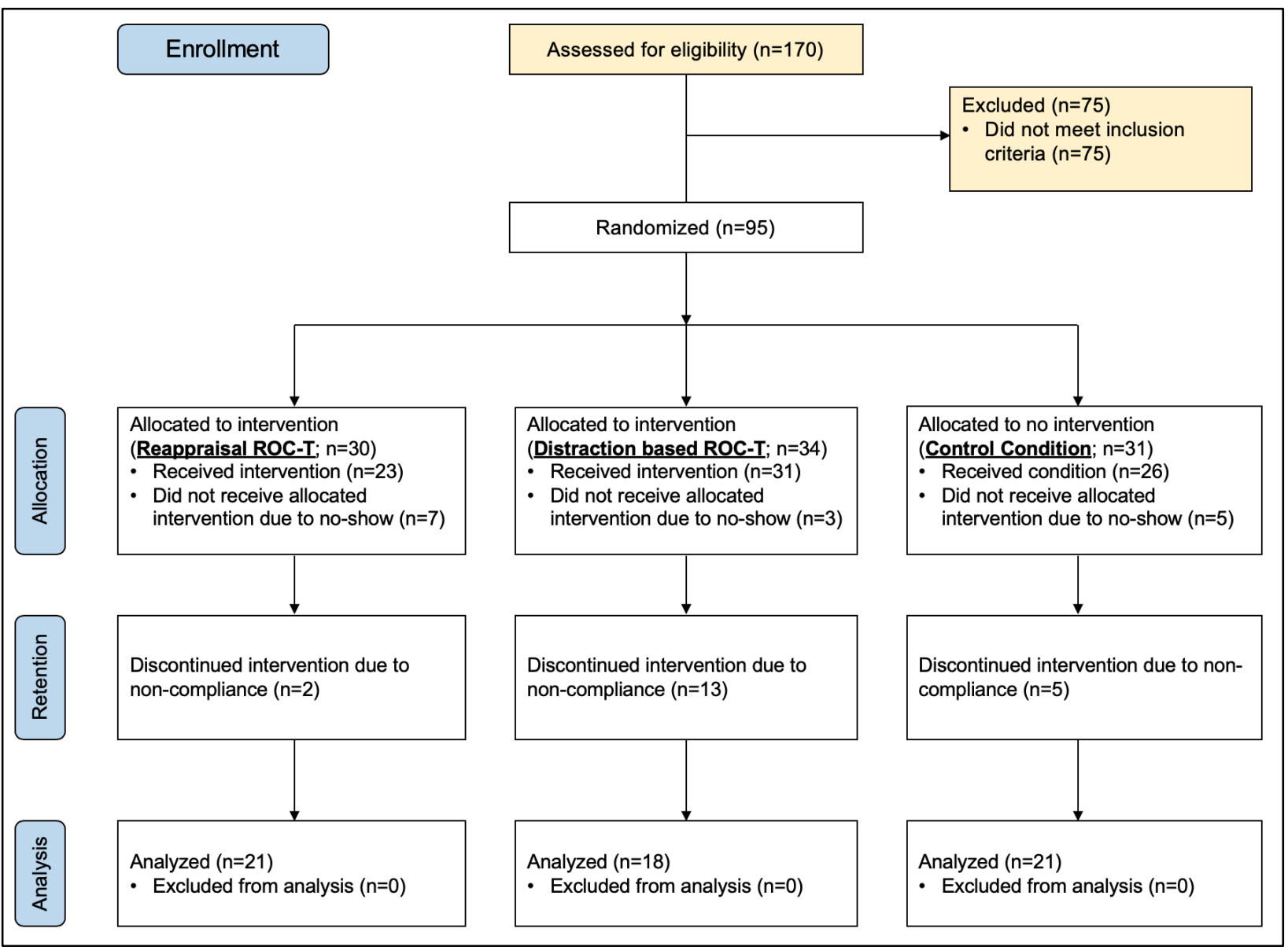



11 disease (COPD).

\section{Cardiovascular Disease:} 19 stroke.

\section{Essay read by participants assigned to the Reappraisal-based ROC-T group}

Every year, about 438,000 people in the United States die of smoking related illnesses.

That is more than AIDS, suicide, alcohol, car accidents, homicide, and illegal drugs combined. Cigarette smoking is responsible for almost 1 in 5 deaths in the United States.

In 1982, the Surgeon General's Report stated, "Smoking is the major single cause of cancer mortality in the United States." This statement remains true in 2008. Cigarette smoking is a behavior that people choose to do, making it the most preventable cause of premature death.

There are numerous illnesses caused by cigarette smoking. The most prevalent and serious among them are: cardiovascular disease, cancer, and chronic obstructive pulmonary

Cardiovascular disease is the leading cause of death due to smoking. It occurs when

4 cholesterol and other fats are deposited in the arteries, making them rigid, narrowed, or completely blocked. This process happens naturally over time, but is accelerated and exacerbated by cigarette smoking. In smokers, the narrowing and hardening of the arteries starts earlier, and blood clots are two to four times more likely to occur. Imagine the constant chest pains, the drastically impaired quality of life, and worst of all, the high risk of heart attack and

Blood clots can travel to different places in the body, blocking the blood vessels, and cutting off blood supply. Coronary thrombosis occurs when a blood clot blocks the arteries that supply the heart, which can lead to a heart attack. During a heart attack, a person experiences sharp pains in the chest that last for several minutes, and are often described as an unbearable pressure or squeezing. Other signs of a heart attack include shortness of breath, nausea, cold 
1 sweats, and light-headedness. Smoking causes about $33 \%$ of all heart attacks.

2 Cerebral thrombosis occurs when the blood vessels that supply the brain become blocked. This

3 can lead to stroke and paralysis. Strokes are characterized by sudden numbness or blindness, an

4 inability to speak or understand, and a loss of balance and coordination. Coronary and cerebral

5 thromboses are the most common causes of sudden death.

\section{Cancer:}

7 Smokers are more likely than non-smokers to get cancer. Some cancers, such as lung

8 cancer, throat cancer, and mouth cancer are common among smokers but hardly ever occur in

9 non-smokers. Other types of cancers that are common among smokers are bladder cancer,

10 esophageal cancer, cervical cancer, and cancers of the kidneys and pancreas. Though there have

11 been many advances in cancer treatment, cancers related with smoking remain some of the most

12 deadly and hard to treat. Imagine the intense pain of treatment, the staggering medical bills, and

13 the depression of dealing with a potentially unbeatable disease.

14 Smoking accounts for more than $90 \%$ of lung cancer cases. Often the cancer has already

15 metastasized and spread beyond the lungs to places like the liver, the brain, and bones before the

16 person notices symptoms and seeks medical attention.

17 When the most common type of lung cancer spread to other chest areas, the five-year

18 survival rate is $5-15 \%$. Once it reaches areas outside of the chest, the five-year survival rate is

19 less than $2 \%$. The second most common type of lung cancer holds a $0-2 \%$ five-year survival rate

20 when it spreads to other areas of the lung.

\section{Chronic Obstructive Pulmonary Disease (COPD):}

22 COPD is a term that refers to a group of illnesses that cause breathing difficulties and

23 block airflow. Between 85 percent and 90 percent of all COPD cases are caused by cigarette 
1 smoking and it is the $4^{\text {th }}$ leading cause of death in the U.S.

2 One illness is emphysema, which is caused by damage to the alveoli of the lungs. This damage

3 inhibits the oxygenation of the body's blood supply and causes a permanent state of

4 breathlessness. Chronic bronchitis is another illness of COPD and is characterized by heavy

5 mucus production and incessant coughing, the irritation from which causes a person to frequently

6 cough up blood. The symptoms of COPD make it virtually impossible to lead a normal life.

7 Imagine the persistent shortness of breathing, the wheezing and coughing, and constant

8 weakness.

9 People with this disease are unable to supply their bodies with the oxygen it needs,

10 causing constant fatigue, and an inability to complete even mildly physical tasks. Severe

11 breathing problems can lead to hospitalization, and eventual death from progressive

12 breathlessness.

\section{Other Health Risks:}

14 There are several other long-term health effects of cigarette smoking. Smokers are twice

15 as likely to get macular degeneration, resulting in blindness, and have an increased risk of

16 cataracts. Additionally, smokers get sick more frequently; on average they take $25 \%$ more sick

17 days than non-smokers.

18 Couples who smoke are more likely to have fertility problems. Women who smoke are

19 more likely to get cervical cancer, which, upon surgical removal, can leave a woman unable to

20 have children. Men who smoke have a 50\% increased risk of erectile dysfunction (ED). This is

21 because smoking damages the blood vessels leading to the penis, resulting in a decreased blood

22 flow and increased impotence. 
12 tobacco.

\section{Brightleaf Tobacco:}

\section{Essay read by participants assigned to the Distraction ROC-T group}

In 1609, Native Americans first introduced European settlers to the tobacco plant.

However, Native Americans were using tobacco recreationally for centuries before introducing it to European settlers. Tobacco was used for currency, religious ceremonies, personal prayer, giftgiving, and leisurely smoking.

Later in 1620, John Rolfe exported 40,000 pounds of tobacco for sale in England.

Throughout the $17^{\text {th }}$ and $18^{\text {th }}$ centuries, tobacco remained the leading cash crop in Virginia and the Carolinas. Last year, about 360 million cigarettes were sold in the United States.

There are numerous types of tobacco that have been developed since then for use in cigarette production. The most popular kinds are: Brightleaf tobacco, white burley, and shade

Brightleaf tobacco was the leading type of tobacco grown for smoking. It became popular in the $19^{\text {th }}$ century, when farmers discovered that it grows robustly when planted in sandy, thin, starved soil, where other crops will not grow. It was first processed using charcoal for heat-curing, but farmers quickly developed new techniques to accelerate the curing process. In areas that were formerly undeveloped, the growth of Brightleaf tobacco led to property values multiplying by 25 to 30 times their initial worth. You can imagine what a boon this was for farmers who had previously been unable to grow crops in areas of poor soil.

Brightleaf tobacco's popularity grew after the end of the Civil War. It had been a favorite of Confederate soldiers, who brought Brightleaf tobacco with them to the front lines, where they traded it with Union soldiers. At the end of the war, soldiers returned home and maintained their preference for this kind of tobacco, which led to a national market for the 
1 formerly local crop. During the antebellum period, Brightleaf became the number one type of

2 tobacco grown in the United States.

3 To this day, Brightleaf tobacco (which is also known as Virginia tobacco) remains a very

4 popular crop among tobacco farmers. In fact, almost all Canadian cigarettes are made from 100\%

5 pure Brightleaf tobacco. The Brightleaf capital of the United States is Pitt County, North

6 Carolina.

7 White Burley:

8 White Burley tobacco was developed from a subtype of Red Burley tobacco, when a

9 farmer noticed that some of the Red Burley plant leaves were paler in color and finer in texture.

10 He began cultivating only the lighter plants, which gave rise to White Burley tobacco. News of

11 this mild tobacco spread quickly across Ohio and the developing Midwest. It was first cultivated

12 and sold in Cincinnati but the demand for it grew, and it quickly began to sell for a premium. It

13 became the main tobacco used for chewing tobacco, American blend pipe tobacco, and

14 American-style cigarettes. Since White Burley has a much milder flavor than Brightleaf, you

15 can imagine why it would become more popular for use in cigarettes.

16 Although White Burley was first developed from Red Burley, the latter is no longer

17 farmed for commercial use. Therefore, people generally refer to the first type as just "Burley,"

18 dropping the color description from its name. $70 \%$ of Burley tobacco that is cultivated today in

19 the United States comes from Kentucky. Another 20\% is grown on farms in Tennessee, with

20 smaller amounts produced in Indiana, North Carolina, Missouri, and Ohio.

\section{Shade Tobacco:}

Shade tobacco refers to the variety of the plant that was grown by Native Americans in

23 the Connecticut River valley, and is still farmed there today. It was originally smoked by Native 
1 Americans and shared with settlers in the area. However it was outlawed in 1650 by the

2 Puritans, who called it "the evil weed."

Cigar smoking increased in the $19^{\text {th }}$ century, and Shade tobacco began to be used as the

4 outer wrapper of cigars. However, each tobacco plant yields only 18 leaves useful as cigar

5 wrappers, and each leaf requires a great deal of individual manual attention during harvesting. It

6 is no longer used for cigarette production. You can imagine how difficult and tedious producing

7 cigars from Shade tobacco must be.

8 In 1921, Shade tobacco production in Connecticut peaked, at 31,000 acres under

9 cultivation. The rise of cigarette smoking and the decline of cigar smoking have caused a

10 corresponding decline in the demand for Shade tobacco, reaching a minimum in 1992 of only

112,000 acres under cultivation.

\section{Other Types of Tobacco:}

13 There are several other kinds of tobacco that are grown around the world, and used for

14 different purposes. Perique tobacco is predominantly grown in Louisiana, and is characterized

15 by a strong, spicy taste. Small amounts of it are usually mixed in to pipe-blends.

16 Dokha is an Iranian tobacco that is often mixed with leaves, bark, and herbs for aromatic

17 smoking in a water-pipe. Other varieties of tobacco are used to make snuff, which is insufflated

18 through the nose, chewing tobacco, which is kept in the mouth for extended periods of time. 
You indicated that you were motivated to reduce or quit smoking. We therefore want you to make a plan to reduce or quit smoking during the next few days.

I will

HOW:

One obstacle to reducing or quitting smoking is craving for cigarettes. Now, we want you to try a behavior that will help you overcome this obstacle: When you feel the desire to smoke, focus on the information you read in the essay today. Recall and think vividly of as many details as possible. For example, you can think about suffering from cardiovascular disease, cerebral thrombosis, lung or throat cancers, chronic obstructive pulmonary disease (COPD), and other long term effects of cigarette smoking.

Before we go on, please tell us, in your own words, the goal you plan to follow. Simply fill in the missing parts:

\section{I will}

\section{And when} , then

WHERE and WHEN: We want you to formulate your plans to use the strategy in as much detail as possible, by identifying obstacles to your goal. Please pay particular attention to the situations in which you will implement these plans. To do so, generate the 10 situations that you think will tempt you to smoke over the next few days and might be obstacles to your goal as you stated above.

For each situation, please plan to use the strategy we proposed.

Example: When I am watching TV at night, I will remember the information I read in the essay today (specify what information you will bring to mind). 
You indicated that you were motivated to reduce or quit smoking. We therefore want you to make a plan to reduce or quit smoking during the next few days.

I will

HOW:

One obstacle to reducing or quitting smoking is craving for cigarettes. Now, we want you to try a behavior that will help you overcome this obstacle: When you feel the desire to smoke, focus on the information you read in the essay today. Recall and think vividly of as many details as possible. For example, you can think about the history of the brightleaf tobacco, white burley tobacco, shade tobacco, or other types of tobacco and their uses.

Before we go on, please tell us, in your own words, the goal you plan to follow. Simply fill in the missing parts:

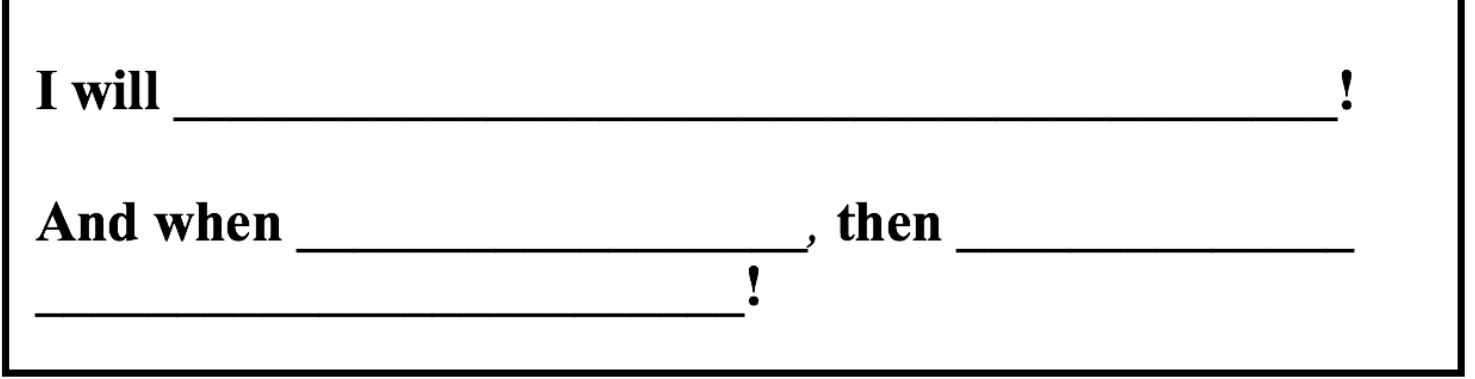

WHERE and WHEN: We want you to formulate your plans to use the strategy in as much detail as possible, by identifying obstacles to your goal. Please pay particular attention to the situations in which you will implement these plans. To do so, generate the 10 situations that you think will tempt you to smoke over the next few days and might be obstacles to your goal as you stated above.

For each situation, please plan to use the strategy we proposed.

Example: When I am watching TV at night, I will remember the information I read in the essay today (specify what information you will bring to mind). 
2 Allen, S. S., Bade, T., Hatsukami, D., \& Center, B. (2008). Craving, withdrawal, and smoking urges on days immediately prior to smoking relapse. Nicotine \& Tobacco Research: Official Journal of the Society for Research on Nicotine and Tobacco, 10(1), 35-45.

Babb, S., Malarcher, A., Schauer, G., Asman, K., \& Jamal, A. (2017). Quitting Smoking Among Adults — United States, 2000-2015. MMWR. Morbidity and Mortality Weekly Report, Vol. 65, pp. 1457-1464. doi:10.15585/mmwr.mm6552a1

Beauchamp, K. G., Kahn, L. E., \& Berkman, E. T. (2016). Does inhibitory control training transfer?: behavioral and neural effects on an untrained emotion regulation task. Social Cognitive and Affective Neuroscience, 11(9), 1374-1382.

Beck, J. S. (2011). Cognitive-behavioral therapy. Clinical Textbook of Addictive Disorders, 491, $474-501$.

Berkman, E. T., Hutcherson, C. A., Livingston, J. L., Kahn, L. E., \& Inzlicht, M. (2017). Selfcontrol as value-based choice. Current Directions in Psychological Science, 26(5), 422428.

Boswell, R. G., Sun, W., Suzuki, S., \& Kober, H. (2018). Training in cognitive strategies reduces eating and improves food choice. Proceedings of the National Academy of Sciences of the United States of America, 115(48), E11238-E11247.

Buhle, J. T., Silvers, J. A., Wager, T. D., Lopez, R., Onyemekwu, C., Kober, H., ... Ochsner, K. N. (2014). Cognitive reappraisal of emotion: a meta-analysis of human neuroimaging studies. Cerebral Cortex , 24(11), 2981-2990.

Carpenter, M. J., Saladin, M. E., DeSantis, S., Gray, K. M., LaRowe, S. D., \& Upadhyaya, H. P. (2009). Laboratory-based, cue-elicited craving and cue reactivity as predictors of naturally 
occurring smoking behavior. Addictive Behaviors, 34(6-7), 536-541.

Carroll, K. M., \& Kiluk, B. D. (2017). Cognitive behavioral interventions for alcohol and drug use disorders: Through the stage model and back again. Psychology of Addictive Behaviors: Journal of the Society of Psychologists in Addictive Behaviors, 31(8), 847-861.

Centers for Disease Control and Prevention (CDC). (2008). Smoking-attributable mortality, years of potential life lost, and productivity losses--United States, 2000-2004 (Vol. 57, pp. 12261228). Retrieved from https://www.ncbi.nlm.nih.gov/pubmed/19008791

Chen, P.-H. A., Kelley, W. M., Lopez, R. B., \& Heatherton, T. F. (2018). Reducing reward responsivity and daily food desires in female dieters through domain-specific training. Social Neuroscience, Vol. 14, pp. 470-483. doi:10.1080/17470919.2018.1495667

Conklin, C. A., Vella, E. J., Joyce, C. J., Salkeld, R. P., Perkins, K. A., \& Parzynski, C. S. (2015). Examining the relationship between cue-induced craving and actual smoking. Experimental and Clinical Psychopharmacology, 23(2), 90-96.

Cooney, N. L., Litt, M. D., Cooney, J. L., Pilkey, D. T., Steinberg, H. R., \& Oncken, C. A. (2007). Alcohol and tobacco cessation in alcohol-dependent smokers: analysis of real-time reports. Psychology of Addictive Behaviors: Journal of the Society of Psychologists in Addictive Behaviors, 21(3), 277-286.

Diekhof, E. K., Kaps, L., Falkai, P., \& Gruber, O. (2012). The role of the human ventral striatum and the medial orbitofrontal cortex in the representation of reward magnitude--An activation likelihood estimation meta-analysis of neuroimaging studies of passive reward expectancy and outcome processing. Neuropsychologia, 50(7), 1252-1266.

Doherty, K., Kinnunen, T., Militello, F. S., \& Garvey, A. J. (1995). Urges to smoke during the first month of abstinence: relationship to relapse and predictors. Psychopharmacology, 119(2), 
$171-178$.

Duckworth, A. L., Gendler, T. S., \& Gross, J. J. (2016). Situational Strategies for Self-Control. Perspectives on Psychological Science: A Journal of the Association for Psychological Science, 11(1), 35-55.

Dutra, L., Stathopoulou, G., Basden, S. L., Leyro, T. M., Powers, M. B., \& Otto, M. W. (2008). A meta-analytic review of psychosocial interventions for substance use disorders. The American Journal of Psychiatry, 165(2), 179-187.

Everitt, B. J., \& Robbins, T. W. (2005). Neural systems of reinforcement for drug addiction: from actions to habits to compulsion. Nature Neuroscience, 8(11), 1481-1489.

Fagerström, K. (2011). Determinants of tobacco use and renaming the FTND to the Fagerström Test for Cigarette Dependence. Nicotine \& Tobacco Research, 14(1), 75-78.

Faul, F., Erdfelder, E., Lang, A. G., \& Buchner, A. (2007). G* Power 3: A flexible statistical power analysis program for the social, behavioral, and biomedical sciences. Behavior Research Methods, 39(2), 175-191.

Ferguson, S. G., \& Shiffman, S. (2009). The relevance and treatment of cue-induced cravings in tobacco dependence. Journal of Substance Abuse Treatment, 36(3), 235-243.

Gass, J. C., Motschman, C. A., \& Tiffany, S. T. (2014). The relationship between craving and tobacco use behavior in laboratory studies: a meta-analysis. Psychology of Addictive Behaviors: Journal of the Society of Psychologists in Addictive Behaviors, 28(4), 11621176.

Giuliani, N. R., Calcott, R. D., \& Berkman, E. T. (2013). Piece of cake. Cognitive reappraisal of food craving. Appetite, 64, 56-61.

Giuliani, N. R., Mann, T., Tomiyama, A. J., \& Berkman, E. T. (2014). Neural Systems Underlying 
the Reappraisal of Personally Craved Foods. Journal of Cognitive Neuroscience, 26(7), 1390-1402.

Goldstein, R. Z., \& Volkow, N. D. (2011). Dysfunction of the prefrontal cortex in addiction: neuroimaging findings and clinical implications. Nature Reviews. Neuroscience, 12(11), $652-669$.

Gross, J. J. (2002). Emotion regulation: Affective, cognitive, and social consequences. Psychophysiology, 39(3), 281-291.

Hartwell, K. J., Johnson, K. A., Li, X., Myrick, H., LeMatty, T., George, M. S., \& Brady, K. T. (2011). Neural correlates of craving and resisting craving for tobacco in nicotine dependent smokers. Addiction Biology, 16(4), 654-666.

Heatherton, T. F., Kozlowski, L. T., Frecker, R. C., \& Fagerström, K. O. (1991). The Fagerström Test for Nicotine Dependence: a revision of the Fagerström Tolerance Questionnaire. British Journal of Addiction, 86(9), 1119-1127.

Jamal, A., Phillips, E., Gentzke, A. S., Homa, D. M., Babb, S. D., King, B. A., \& Neff, L. J. (2018). Current Cigarette Smoking Among Adults - United States, 2016. MMWR. Morbidity and Mortality Weekly Report, 67(2), 53-59.

Kiluk, B. D., Nich, C., Babuscio, T., \& Carroll, K. M. (2010). Quality versus quantity: acquisition of coping skills following computerized cognitive--behavioral therapy for substance use disorders. Addiction , 105(12), 2120-2127.

Kober, H., Turza, A. C., \& Hart, C. L. (2009). Risk factors for substance use, abuse, and dependence: learning. In Encyclopedia of Drugs, Alcohol, and Addictive Behavior. Macmillan Reference.

Kober, Hedy, Brewer, J. A., Height, K. L., \& Sinha, R. (2017). Neural stress reactivity relates to 
smoking outcomes and differentiates between mindfulness and cognitive-behavioral treatments. NeuroImage, 151, 4-13.

Kober, Hedy, Kross, E. F., Mischel, W., Hart, C. L., \& Ochsner, K. N. (2010). Regulation of craving by cognitive strategies in cigarette smokers. Drug and Alcohol Dependence, $106(1), 52-55$.

Kober, Hedy, Mende-Siedlecki, P., Kross, E. F., Weber, J., Mischel, W., Hart, C. L., \& Ochsner, K. N. (2010). Prefrontal-striatal pathway underlies cognitive regulation of craving. Proceedings of the National Academy of Sciences of the United States of America, 107(33), $14811-14816$.

Koob, G. F., \& Le Moal, M. (2001). Drug addiction, dysregulation of reward, and allostasis. Neuropsychopharmacology: Official Publication of the American College of Neuropsychopharmacology, 24(2), 97-129.

Litt, M. D., Kadden, R. M., Cooney, N. L., \& Kabela, E. (2003). Coping skills and treatment outcomes in cognitive-behavioral and interactional group therapy for alcoholism. Journal of Consulting and Clinical Psychology, 71(1), 118-128.

Litt, M. D., Kadden, R. M., Kabela-Cormier, E., \& Petry, N. M. (2008). Coping skills training and contingency management treatments for marijuana dependence: exploring mechanisms of behavior change. Addiction , 103(4), 638-648.

Lopez, R. B., Onyemekwu, C., Hart, C. L., Ochsner, K. N., \& Kober, H. (2015). Boundary conditions of methamphetamine craving. Experimental and Clinical Psychopharmacology, 23(6), 436-444.

Luijten, M., van Meel, C. S., \& Franken, I. H. A. (2011). Diminished error processing in smokers during smoking cue exposure. Pharmacology, Biochemistry, and Behavior, 97(3), 514- 
520.

2 Marsch, L. A., Carroll, K. M., \& Kiluk, B. D. (2014). Technology-based interventions for the treatment and recovery management of substance use disorders: a JSAT special issue. Journal of Substance Abuse Treatment, 46(1), 1-4.

Mokdad, A. H., Marks, J. S., Stroup, D. F., \& Gerberding, J. L. (2004). Actual causes of death in the United States, 2000. JAMA: The Journal of the American Medical Association, 291(10), 1238-1245.

Naqvi, N. H., \& Morgenstern, J. (2015). Cognitive Neuroscience Approaches to Understanding Behavior Change in Alcohol Use Disorder Treatments. Alcohol Research: Current Reviews, 37(1), 29-38.

Naqvi, N. H., Ochsner, K. N., Kober, H., Kuerbis, A., Feng, T., Wall, M., \& Morgenstern, J. (2015). Cognitive Regulation of Craving in Alcohol-Dependent and Social Drinkers. Alcoholism: Clinical and Experimental Research, Vol. 39, pp. 343-349. doi:10.1111/acer.12637

National Center for Chronic Disease Prevention and Health Promotion (US) Office on Smoking and Health. (2014). The Health Consequences of Smoking—50 Years of Progress: A Report of the Surgeon General. Atlanta (GA): Centers for Disease Control and Prevention (US).

North American Quitline Consortium (2021). Report on the Impact of the COVID-19 Pandemic on Smoking Cessation.

https://cdn.ymaws.com/www.naquitline.org/resource/resmgr/reportsnaqc/report_impact_of_covid-19_p.pdf

O’Connell, K. A., Hosein, V. L., Schwartz, J. E., \& Leibowitz, R. Q. (2007). How does coping help people resist lapses during smoking cessation? Health Psychology: Official Journal 
of the Division of Health Psychology, American Psychological Association, 26(1), 77-84.

Onken, L. S., Carroll, K. M., Shoham, V., Cuthbert, B. N., \& Riddle, M. (2014). Reenvisioning Clinical Science: Unifying the Discipline to Improve the Public Health. Clinical Psychological Science, 2(1), 22-34.

Patanavanich, R., \& Glantz, S. A. (2020). Smoking Is Associated With COVID-19 Progression: A Meta-analysis. Nicotine \& Tobacco Research: Official Journal of the Society for Research on Nicotine and Tobacco, 22(9), 1653-1656.

Pelletier, L. G., Dion, S. C., \& Slovinec-D’Angelo, M. (2004). Why Do You Regulate What You Eat? Relationships Between Forms of Regulation, Eating Behaviors, Sustained Dietary Behavior Change, and Psychological Adjustment - Springer. Motivation and .... Retrieved from http://www.springerlink.com/index/L73756851Q4208U1.pdf

Price, M., Yuen, E. K., Goetter, E. M., Herbert, J. D., Forman, E. M., Acierno, R., \& Ruggiero, K. J. (2014). mHealth: a mechanism to deliver more accessible, more effective mental health care. Clinical Psychology \& Psychotherapy, 21(5), 427-436.

Purkayastha, A., Sen, C., Garcia, G., Jr, Langerman, J., Shia, D. W., Meneses, L. K., ... Gomperts, B. N. (2020). Direct Exposure to SARS-CoV-2 and Cigarette Smoke Increases Infection Severity and Alters the Stem Cell-Derived Airway Repair Response. Cell Stem Cell, 27(6), 869-875.e4.

Reader, S. W., Lopez, R. B., \& Denny, B. T. (2018). Cognitive reappraisal of low-calorie food predicts real-world craving and consumption of high- and low-calorie foods in daily life. Appetite, 131, 44-52.

Rigotti, N. A., Chang, Y., Regan, S., Lee, S., Kelley, J. H. K., Davis, E., Levy, D. E., Singer, D. E., \& Tindle, H. A. (2021). Cigarette Smoking and Risk Perceptions During the COVID- 
19 Pandemic Reported by Recently Hospitalized Participants in a Smoking Cessation Trial. Journal of General Internal Medicine, 36(12), 3786-3793.

Roos, C. R., Kober, H., Trull, T. J., MacLean, R. R., \& Mun, C. J. (2020). Intensive Longitudinal Methods for Studying the Role of Self-Regulation Strategies in Substance Use Behavior Change. Current Addiction Reports. doi:10.1007/s40429-020-00329-5

Rostron, B. L., Chang, C. M., \& Pechacek, T. F. (2014). Estimation of cigarette smokingattributable morbidity in the United States. JAMA Internal Medicine, 174(12), 1922-1928.

Schueller, S. M., \& Torous, J. (2020). Scaling evidence-based treatments through digital mental health. The American Psychologist, 75(8), 1093-1104.

Senécal, C., Nouwen, A., \& White, D. (2000). Motivation and dietary self-care in adults with diabetes: are self-efficacy and autonomous self-regulation complementary or competing constructs? Health Psychology: Official Journal of the Division of Health Psychology, American Psychological Association, 19(5), 452-457.

Shadel, W. G., Martino, S. C., Setodji, C., Cervone, D., Witkiewitz, K., Beckjord, E. B., ... Shih, R. (2011). Lapse-induced surges in craving influence relapse in adult smokers: an experimental investigation. Health Psychology: Official Journal of the Division of Health Psychology, American Psychological Association, 30(5), 588-596.

Shiffman, S., Engberg, J. B., Paty, J. A., Perz, W. G., Gnys, M., Kassel, J. D., \& Hickcox, M. (1997). A day at a time: predicting smoking lapse from daily urge. Journal of Abnormal Psychology, 106(1), 104-116.

Sun, W., \& Kober, H. (2020). Regulating food craving: From mechanisms to interventions. Physiology \& Behavior, 222, 112878.

Suzuki, S., Mell, M. M., O’Malley, S. S., Krystal, J. H., Anticevic, A., \& Kober, H. (2020). 
Regulation of Craving and Negative Emotion in Alcohol Use Disorder. Biological Psychiatry. Cognitive Neuroscience and Neuroimaging, 5(2), 239-250.

Vafaie, N. \& Kober, H. (in revision). Drug Cues and Craving Predict Drug Use and Relapse: A Comprehensive Meta-Analysis.

Volkow, N. D., Fowler, J. S., Wang, G.-J., Telang, F., Logan, J., Jayne, M., ... Swanson, J. M. (2010). Cognitive control of drug craving inhibits brain reward regions in cocaine abusers. NeuroImage, 49(3), 2536-2543.

Waters, A. J., Shiffman, S., Sayette, M. A., Paty, J. A., Gwaltney, C. J., \& Balabanis, M. H. (2004). Cue-provoked craving and nicotine replacement therapy in smoking cessation. Journal of Consulting and Clinical Psychology, 72(6), 1136-1143.

Williams, G. G., Gagné, M., Ryan, R. M., \& Deci, E. L. (2002). Facilitating autonomous motivation for smoking cessation. Health Psychology, Vol. 21, pp. 40-50. doi:10.1037//0278-6133.21.1.40

Witkiewitz, K., Roos, C. R., Mann, K., \& Kranzler, H. R. (2019). Advancing Precision Medicine for Alcohol Use Disorder: Replication and Extension of Reward Drinking as a Predictor of Naltrexone Response. Alcoholism, Clinical and Experimental Research, 43(11), 23952405. 